\title{
3 A paradox of truth minimalism*
}

\author{
Manuel García-Carpintero
}

\subsection{Introduction}

Disquotational accounts of truth are commonly subject to a number of objections. As it happens, however, there are several different ways of understanding disquotationalism; evaluating the criticisms requires sorting out these different interpretations. I shall distinguish 'minimalist' from 'semanticist' disquotationalism, and argue that only the latter is really consistent with what are commonly taken to be the core ideas of disquotationalism. The fundamental difference lies in the following: minimalism is an attempt to elucidate disquotational ideas by means of a semantically very sparse machinery, avoiding any substantial semantic commitment. This is because, in one way or other, minimalist disquotationalism is driven by the desire to produce a deflationist account of content. This desire, though, is alien to the project of offering a disquotational account of truth. What is even worse, in my view, it is at odds with it: thereby the paradox. Without attempting a defence of the semantic conception, in this paper I shall concentrate on arguing that minimalist disquotationalism does not follow from disquotational ideas, but is prima facie at odds with them, and I shall put forward some difficulties for minimalist theories. In the first section I set out briefly what I take to be the main differences between the two ways of understanding disquotational ideas. In the second, I develop the paradox which I find in minimalism. In the third, I present some related difficulties for minimalism, which may help the reader further to make out the differences between the two accounts, and which can provide further support for semanticist disquotationalism. 


\subsection{Minimalist versus semanticist disquotationalism}

In a recent paper, Hartry Field describes in this way what he calls 'purely disquotational truth':

As a rough heuristic, we could say that for a person to call an utterance true in this pure disquotational sense is to say that it is true-as-he-understands-it. ... As the heuristic suggests, a person can meaningfully apply 'true' in the pure disquotational sense only to utterances that he has some understanding of; and for such an utterance $u$, the claim that $u$ is true (true-as-he-understands-it) is cognitively equivalent (for the person) to $u$ itself (as he understands it) (Field, 1994a, p. 250).

Field explains the 'cognitive equivalence' of two sentences for a person in terms of the notion

that the person's inferential procedures license a fairly direct inference from any sentence containing an occurrence of one to the corresponding sentence with an occurrence of the other substituted for it $[\ldots]$ the claim of cognitive significance [...] imply that the inferences are more or less indefeasible (lbid., p. 251).

Field's 'pure disquotational truth' embodies in my view the minimal core common to all disquotational views. According to these views, 'truth' is, in its most basic use, a predicate of utterances of the declarative sentences of our language, whose use we have already mastered; and its content is such that, for any possible utterance of a sentence we understand, predicating truth of it is equivalent to the statement made in uttering the sentence in the same context relative to which it is uttered. The fact that instances of Tarski's schema $T$, involving our own intuitive truth-predicate, where the same 'eternal' sentence of our language is mentioned on the left-hand side and used on the right-hand side, are as close to being 'analytic' ('cognitively equivalent') as any purported paradigmatic instance of the analytic could be (Tarski calls these instances 'partial definitions of truth', my emphasis), counts as empirical indication that pure disquotational truth is not unrelated to the intuitive truth-concept.

There is an immediate consequence of this minimal contention relevant to our ultimate concerns which is worth stating right away. The contention presupposes that a philosophically enlightening characterization of the meaning of the truth-bearers is not to be given in terms of 'truth'. To put it epistemically, our linguistic competence relative to those sentences which are the primary bearers of truth cannot literally consist in anything involving possession of a truth concept. Let us call whatever is asserted when meaningful assertion of a declarative sentence is produced its content. A disquotational account makes the correct predication of 'true' of a sentence conditional on whether or not its content obtains. Because of that, a disquotational account legitimizes a characterization of contents as truth conditions: their obtaining are the necessary and sufficient conditions for the application of 'true' to truth-bearers. But this is just a redescription, without substantive import. A substantive philosophical characterization of contents should be looked for elsewhere.

A device understood along the lines of pure disquotational truth would appear to have a 'redundant' character. What would be its point? Several writers have convincingly identified it: a predicate with the outlined characteristics might be very serviceable to give the benefits of 'semantic ascent'. It will come in handy to give content to claims such as these: 'every sentence which is the disjunction of a sentence and its negation is true', 'some sentence in infinite class $C$ is not true', 'the sentence which A uttered is true'-claims whose intended domain of quantification is of course constituted by the sentences for which the predicate has been introduced. (Compare Quine, 1970, pp. 10-13, and the entry 'Truth' in Quine, 1987. See also Leeds, 1978 and Field, 1986 I.2.) Now, for a truth-predicate to properly serve this purpose, it ought to have been properly defined over the intended domain: for only in that case might the contention be justified that, when we state generalizations of the sort previously exemplified, we are doing 'essentially' nothing more than abbreviating to our convenience long (perhaps infinite) disjunctions or conjunctions of statements themselves not involving the truth-predicate.

This presents an immediate challenge to the claim that disquotationalism captures the way the intuitive truth predicate works. Any truth-predicate introduced following the principle that $T$-sentences embody a fundamental portion of its content raises the spectre of the semantic antinomies. On this issue, I will simply assume that there is a way of avoiding the antinomies compatible with any of the views on truth and meaning to be contemplated here.

The two varieties of disquotationalism I mentioned at the beginning split paths here. The sort of vindication of disquotationalism that was initiated by Alfred Tarski in §§2-3 of his classic Tarski (1935) aims to produce either an explicit definition having as consequences the relevant $\mathrm{T}$-sentences-or at least an axiomatic account with the saine consequences-by relying on a heavy semantic machinery. Such a form of disquotationalism displays semantic information about the object language, and at the very least can be taken as a good heuristic for the project of advancing a semantic theory for the object language. However, it has been claimed by several philosophers 
(starting with Michael Dummett, see Dummett, 1978) that no disquotational truth-definition can, in any way, pass as a 'theory of meaning'. Sometimes this has been argued for on the basis of considerations like one I already granted a few paragraphs back; namely, that a philosophically enlightening characterization of the meaning of the truth-bearers is not to be given in terms of 'truth'. As Michael Dummett puts it in a paper which is included in this same volume:

Nothing can be simultaneously a theory and a definition. A semantic theory may incorporate a definition of truth, in the sense of laying down what it is for an (indexed) sentence to be true; but it cannot embody a definition of truth that consists in a means of speeifying the condition for each such sentence to be true, because there would then be no more work for the theory to do (Dummett, this volume, p. 5).

As I have explained elsewhere (García-Carpintero, forthcoming-a), there is a danger of potential confusion in this train of reasoning, which is actualized in the writings of some philosophers. Let us distinguish a linguistic theory of meaning from a philosophical theory of meaning. A linguistic theory of meaning attempts to make explicit the laws that determine the meaning of complex expressions from the meaning of lexical units and their logical category. A linguistic theory of meaning assumes that there are in natural languages linguistic expressions which have meanings in isolation, without the need of being taken together with other linguistic expressions: sentences or utterances thereof, in the more atomistic conception, or maybe larger 'units', like discourses, or whole fragments of languages, in more holistic views. It presupposes also (on the basis of well-known inductively supported considerations) that the meanings of these units that have them in isolation are systematically determined on the basis of the meanings of semantic units, whose meaning is not determined from the meanings of their parts, but which, on the other hand, cannot have meaning in isolation. The theoretical goal of a linguistic theory of meaning, therefore, is to provide what is traditionally understood as a compositional theory for the language under consideration.

The philosophers who advance the criticism I indicated in the previous paragraph complain-in their support-that Tarskian truth theories are given for specific languages, and also that they rely at some point or other on definitions by enumeration of some semantic properties. Thus Dummett again, 'it would be a strange account of meaning that applied only to English sentences, and could not be extended to sentences of other languages' (op. cit., p. 9); 'as an explanation that will satisfy a philosopher wishing to know what constitutes a sentence's having whatever meaning it has, it is sadly deficient' (ibid., p. 10). Similarly, Davidson says:

[...] Tarski's definitions give us no idea how to apply the concept to a new case whether the new case is a new language or a word newly added to a language [...] This feature of Tarski's definitions can in turn easily be traced back to the fact tha they depend on giving the extension or reference of the basic predicates or names by enumerating cases: a definition given in this way can provide no clue for the next or general case (Davidson, 1990, p. 287).

And: 'the central point is this: aside from our grasp of the concept of translation, convention- $T$ gives us no idea how to tell in general when one of Tarski's truth predicates applies to a particular language. He does not define the concept of translation'. (Davidson, 1990, pp. 295-6).

These complaints, however, are out of order when addressed to the issue of whether or not a theory of truth can embody a linguistic theory of meaning theory. For, firstly, it is perfectly in order that linguistic theories of meaning are restricted to specific languages (even if Spanish, or the Spanish that I speak, were the only language that had ever existed, it would still be worthwhile to construe a compositionality theory for it). Secondly, it is inevitable that they rely on lists, for systematically determined linguistic properties are so determined on the basis of asystematically determined ones: that is to say, on the basis of properties whose extension is linguistically determined by enumeration. And, finally, there is no objection to the fact that they assume an already understood concept of content for the complex expressions that have their meanings in isolation (or, as Davidson says, a 'concept of translation'), because it is not their theoretical business to account for it.

Notice that I have only conceded that a disquotational account, by itself, cannot provide a philosophical theory of meaning. John McDowell says:

If there can be such a thing as a theory of meaning for any language, meaning cannot be anything but what any such theory is a theory of. Hence a clear and convincing description of the shape which a theory of meaning for any language would take, not itself uncritically employing the notion of meaning, ought to remove all perplexity about the nature of meaning in general (McDowell, 1976, p. 42; my emphasis).

The disquotationalism of the semantic account of truth indeed employs 'uncritically' the notion of meaning as applied to what the theory takes to be truth-bearers: say, meaningful utterances of declarative sentences, or declarative sentences themselves if they are 'eternal' (or perhaps whole classes of one or the other). The account takes for granted that we know what meanings are, and also that there are such properties; and claims that the truth-concept could be correctly explicated by offering an explicit definition 
(or an axiomatic characterization) of a predicate which generates every instance of schema- $T$, which is itself characterized uncritically using the concept of meaning.

An account with such assumptions cannot satisfy a philosopher, for it does not say in general terms what the meaning of utterances of declarative sentences is (even though this can plausibly be taken as the basic case for the meaning-relation), nor does it show how meanings could be integrated with other natural properties the meaning-bearers might have (although it should, for meanings are taken to be causal-explanatory properties, and it is a plausible general requirement on such properties that they can be integrated for explanatory purposes with other natural properties, ultimately with basic physical properties). Moreover, as we saw, the semantic conception presupposes that such a philosophical theory of meaning should be given without essential use of the concept of truth. But all of this is compatible with the account being an informative part of a linguistic theory of meaning. It may be thought, in terms of the distinction I have been making, that the criticisms I have so far considered may well be exclusively concerned with the issue of whether or not the concept of truth is needed in a philosophical theory of meaning. But, firstly, it is important to clarify what is being discussed. If understood in that way, the arguments by Dummett and Davidson indicated before lack any force; for the semantic conception of truth is not intended to serve as a philosophical account of meaning. ${ }^{1}$ And, secondly, some writers have explicitly denied that a disquotational account of truth can provide what I have been describing as a linguistic theory of meaning (see, for instance, Soames, 1984 and Etchemendy, 1988; Dummett, this volume endorses Etchemendy's contentions). ${ }^{2}$

The semantic version of disquotationalism, thus, is characterized by its use of an important semantic machinery, and by its capacity to serve as a partial linguistic theory of meaning: a partial compositionality theory for the object language. Minirnalism is the view that purports to combine disquotationalism with the contention that a philosophical account of truth can be given even without that semantic machinery.

Minimalism comes in two varieties: propositional, and linguistic. Propositional minimalists take propositions as primary truth-bearers; they explain truth for linguistic items derivatively, on the basis of a simple schema: if $\mathrm{S}$ expresses the proposition that $p$, then $\mathrm{S}$ is true iff $p$. My attribution of a paradoxical character to minimalism was not intended against this version of the account. I think there are reasons not to be satisfied with it, but I do not find in it any incoherence. A reason not to be satisfied with propositional minimalism is a version of one of the arguments I will later address against the linguistic variety (see later, section 3.3); it is a point analogous to one made in Gupta (1993). At present, however, its main difficulty is one of formulation; this is made manifestly clear by the problems besetting the only attempt I know of at giving a precise statement of propositional minimalism, that of Horwich (1990). ${ }^{3}$ In my view, this difficulty is not at all accidental. Propositions are, essentially, theoretical entities; they are entities which we need to introduce to make theoretical distinctions between several aspects of what we, pretheoretically, take to be the meaning, or 'content', of prototypical bearers of meaning: utterances or thoughts in specific contexts. I do not mean these remarks in a sceptical frame of mind. I do not have any doubts regarding the existence of propositions, not even when they are understood in a deeply realistic way: there certainly are, in my view, propositions not actually expressed in any human language, and perhaps even propositions not expressible in any human language. Still, I would find it very strange that such a usual or and fundamental concept as truth be predicated, in its basic usage, of propositions so understood. I think a case can be made that 'truth' should be predicated of linguistic items relative to the proposition they express (and independently of their specific illocutionary force); but this is not the same thing as claiming that 'truth' is predicated of propositions.

What I certainly do not find at all convincing is the propositional minimalist's suggestion that it can be established, just on the basis of intuitions regarding some examples ('Goldbach's conjecture is true'), that the ordinary truthconcept applies to propositions (this suggestion is intimated in Soames's writings; see the beginning of Soames, 1984, and Soames, forthcoming). As far as I can see, whatever intuitions ordinary speakers may have on those examples are compatible with the relevant truth-bearers being, for instance, Tractarian 'propositions' (that is to say, interpreted sentences). This is what should be expected, given the highly theoretical character of propositions; it suggests, as I indicated, that the order of explanation should be the opposite to what propositional minimalists contemplate. I am aware of the impressionistic nature of these remarks against propositional minimalism; but the target view has not been successfully developed, at the present stage, in anything more than an impressionistic way, and the arguments its defenders provide are equally impressionistic. (Soames, for instance, finds it similarly difficult to believe that a concept as ordinary as truth should be explained in terms of an imposing semantic machinery. But many familiar-looking concepts, like that of grammatically correct sentence, are to be explained in terms of an imposing theoretical machinery.) In any case, something should at least be clear: against recent claims by propositional minimalists like Paul Horwich, propositional minimalism about truth is irrelevant regarding the 
project of giving a deflationary account of meaning. ${ }^{4}$ An account of meaning is an account of how speech acts acquire a propositional content. An account of truth for propositions, no matter how minimal, is of no use for this project. It is only in linguistic minimalism that deflationists about meaning may hope to find some support for their views.

\subsection{The main difficulty for linguistic minimalism}

Linguistic minimalism is defended in several recent writings by Hartry Field (see Field, 1994a and 1994b), and Horwich claims throughout his book that an account as minimal as the one he gives for propositions can be given for linguistic entities. The spirit of the view is well captured by the sort of definition that their defenders sympathize with: it has to be one which makes the truth predicate a disquotational one, and it is given without relying on a complex semantic machinery. Such a definition could be given, for instance, by means of substitutional quantification, or equivalent methods (like a metatheory capable of manipulating sentence-schemata). The definition could be: $\forall \sigma(\sigma$ is true in L iff $\Sigma \rho(\sigma=$ ' $\rho$ ' $\wedge \rho)$ ), where ' $\Sigma$ ' represents the existential substitutional quantifier and $\mathrm{L}$ is the language for which the definition is given..$^{5}$ A predicate so defined can at first sight be thought to satisfy a condition of 'use-independence' which Field spells out in this way: 'the property of those sentences which it defines is one that a sentence has or fails to have independently of the way that the sentence is used by speakers' (Field, 1986 , p. 58). For the definition, being given by means of substitutional quantifiers, only identifies the truth-bearers by their non-semantic, formal properties. However, no matter what the appearances may be, no disquotational truth-predicate can be 'use-independent', in Field's sense, and no adequate account of truth can be given by means of the sort of definition Field has in mind.

Field clarifies the content of the use-independence condition indicating that a user-independent disquotational predicate 'true' would be such that

the sentence

$\mathrm{C}_{1}$ if we had used the word 'white' differently, 'grass is white' might have been true

is equivalent to

$\mathrm{C}_{2}$ if we had used the word 'white' differently, grass might have been white (Field, 1986, 58; compare Field, 1994a, pp. 259-60).
Curiously enough, some philosophers (especially Putnam, but also Soames and Etchemendy) have taken the fact that, according to them, disquotational truth-predicates have precisely this consequence (the equivalence of sentences like $C_{1}$ to sentences like $C_{2}$ ) as clear indication that disquotational truth has nothing to do with intuitive truth. Field, on the other hand, takes the entailment of such equivalencies as constitutive of purely disquotational truth predicates. (He proposes to capture the intuitions handled by those other philosophers by introducing related, not 'purely disquotational' truthpredicates. See Field, 1994a, §9.) To elucidate further the shape of the semantic account of truth, as I understand it, and to present the paradox I see in linguistic minimalism, it will be convenient to start by showing why the argument by Etchemendy, Putnam and Soames is invalid, and why a properly understood disquotational theory cannot be 'use-independent'.

Putnam (1985) argues in this way. Let us use 'true ${ }_{I}$ ' to express the intuitive truth-concept and 'true $e_{D}$ ' to express one defined according to disquotational guidelines; and let us think of the domain for both predicates as consisting of the sentences belonging to a certain language L. Because nothing in Putnam's argument or in my reply depends on the language having any complexity, and for the sake of clarity, we can think of $L$ as having just one sentence, "snow is white', having in L the same meaning it has in English. The truth definition would then be easy:

(D) For every sentence $\sigma$ of $L, \sigma$ is true $e_{D}$ if and only if $\sigma=$ 'snow is white' and snow is white.

Now, because the intuitive concept of truth is linked to the concept of meaning, there are certain modal claims involving 'true ${ }_{\mathrm{I}}$ ' which seem intuitively correct. For instance, 'snow is white' might have had a different meaning in $\mathrm{L}$; that is to say, there is a possible counterfactual circumstance $w$ involving $\mathrm{L}$ in which 'snow is white' means something different, say, that grass is yellow. In that possible circumstance, (i) the conditions for application of 'true ${ }_{\mathrm{I}}$ ' to L's sentences would change accordingly, and as a result (ii) the color of snow in that counterfactual circumstance would be irrelevant to determining whether or not 'true ${ }_{\bar{T}}$ ' applies to 'snow is white': even if we assumed that the color of snow was the same in $w$ as it is in the actual world, that would not imply that 'true $e_{\mathrm{I}}$ applies to 'snow is white' in $w$. However, it seems that (i) and (ii) are false when we consider 'true ${ }_{\mathrm{D}}$ ' instead of 'true,'. For it logically follows from the definition of 'true $\mathrm{D}_{\mathrm{D}}$ ' the T-sentence "."snow is white" is a true $e_{D}$ sentence of $L$ if and only if snow is white.' (The fact-if it is a fact, which is something I am about to dispute-that the Tsentence 'logically follows' from the definition does not depend on the 
simplicity of the language, only on the possibility of having an explicit definition. If the language is more interesting, some further mathematical facts are required; but they can be safely assumed to hold in every possible world.) This being a logically valid equivalence, it must hold in every possible circumstance. Thus, also in $w$, (i') the conditions for application of 'true ${ }_{\mathrm{D}}$ ' will not change, and (ii') given that snow is white in $w$, 'snow is white' is a true $e_{D}$ sentence of $L$ in $w$.

On the understanding of disquotationalism I take to inform the semantic conception of truth, this argument is fallacious. Putnam takes the predicate 'true ${ }_{D}$ ' to have been defined, as it were, stipulatively; this is why he says that the T-sentences are (essentially) 'logically true'. But it is not the case that 'true ${ }_{\mathrm{D}}$ ' has been defined stipulatively, as I have argued elsewhere (see GarcíaCarpintero 1996, and forthcoming-a). If it were, it would not make sense to consider whether or not it is correct that 'true ${ }_{D}$ ' applies to the sentence of $L$ 'snow is white': the stipulation stipulates that it applies on the condition that snow is white, and snow is white, so the predicate applies to the sentence: there is no more to argue about. However, it does make sense to consider whether or not it is correct that the predicate applies to the sentence.

A way of accounting for this is to say that there is more in what is asserted when 'true ${ }_{D}$ ' is ascribed to a sentence of $L$ than Putnam and the other writers assume. It is also asserted that the sentence used in the right-hand-side of the T-sentences generated by the definition means the same as the sentence mentioned in the left-hand-side means in fact in L. When the definition is given in a language that includes the object-language, a speaker who understands the defined tuth-predicate in the proposed way can still establish, only on the basis of his understanding of the expressions involved, that any given T-sentence is true. (Needless to say, if they are; that is to say, if the definition is, to that extent, correct, or 'materially adequate' as Tarski puts it.) Thus, in that special case T-sentences including the defined truthpredicate are still 'analytic' (understanding 'analytic' in an epistemic sense: known to be true on the basis of semantic knowledge only). Both sides are also 'cognitively equivalent', as Field wants; which is as it should be. But they are not 'logically true', in the sense which is needed for Putnam's argument.

On the basis of this account, there are two possible ways in which to treat Putnam's modal considerations. We can just say that L-in-w is a different language from L-in-the-actual-world (L-as-I-understand-it, paraphrasing Field); for present purposes, we take every semantic property of a language which is relevant to construing a correct truth-definition as essential Therefore, nothing follows from the truth-definition for 'true ${ }_{D}$ ' regarding the application of the predicate to 'snow is white' in $w$. Thus, (ii') is false, and, in that respect, 'true $e_{\mathrm{D}}$ ' agrees with 'true $\mathrm{I}_{\mathrm{I}}$. What is more, although nothing follows from the truth-definition for 'true $\mathrm{D}_{\mathrm{D}}$ ' regarding the truth predicate for the different language spoken in $w$, L-in- $w$, the notion that a generalization from the previously outlined condition (in essence, Tarski's Convention T) captures the essence of disquotational truth-predicates allows us to predict that the conditions for application of a disquotational truth-predicate for L-in$w$ might well differ from those for a truth-predicate for L-in-the-actualworld-to the extent that the semantics of these two languages differ. In that sense, (i') is also false, and thus the agreement with the pretheoretic judgements is complete. Alternatively, we may admit that although small semantic variations can affect the truth-conditions of some sentences, they are compatible with the identity of the language being preserved. In that case, we have to distinguish L-as-it-actually-is from L-as-it-might-have-been, and assume that 'true $\mathrm{D}_{\mathrm{D}}$ ' is defined for L-as-it-actually-is and not for L-as-it-mighthave-been. The net result as far as Putnam's considerations are concerned is exactly the same as before.

The reader might think that these are desperate ad hoc manoeuvres, designed for the exclusive purpose of salvaging the semantic conception from Putnam's 'refutation'. But this would be a mistake. Far from being ad hoc, the preceding contentions follow directly from the essential point of disquotationalism. The essential point is that the conditions that have to obtain for the truth-predicate to apply to one of its candidate linguistic truthbearers are precisely the conditions signified by the candidate; and thus, that we can properly give the content of the truth-predicate if we either explicitly define it, or give an axiomatic characterization of it, so that the account entails, for évery candidate, a biconditional in whose left-hand side the truthpredicate is ascribed to it and in whose right-hand side a sentence with its same meaning is asserted. Thus, if we are to consider the truth-conditions of an ascription of the defined truth-predicate in counterfactual circumstances, we can take either of the preceding altematives: we can either assume that 'true ${ }_{D}$ ' has been defined for sentences of a language whose counterpart in a different possible world is not a language with different relevant semantic properties; or we can assume that 'true $e_{D}$ ' has been defined only for sentences of the language as it actually is. In both cases, it follows from the essential tenet of the semantic conception that a Tarskian truth-definition does not authorize us to ascribe the defined predicate to the sentence 'snow is wlite', no matter what semantic properties it has in the language to which it belongs, only on the basis that the condition which the sentence as a matter of fact asserts, given the actual semantics of the language for which the definition has been given, is satisfied. 
Here, then, lies the paradox of linguistic minimalism. If these considerations are correct, no disquotational truth-concept can be 'useindependent'. A disquotational truth-predicate would have to be one defined for sentences that have certain semantic properties and to the extent that they have those specific semantic properties. Given the hypothesis of $\mathrm{C}_{1}$ above (in Field's characterization of 'use-independence')-i.e., relative to possible circumstances where the same sentence has different semantic properties-thus, the definition of a disquotational truth-predicate does not give any indication about the conditions in which the predicate would apply to that sentence. The cognitive equivalence of " "grass is white" is true' and 'grass is white' does not authorize the move from $C_{1}$ to $C_{2}$, or vice versa. Thus, a disquotational truth-predicate does not make $C_{1}$ and $C_{2}$ equivalent, and cannot be 'use-independent'.

Let us examine this point more carefully. In the case Field is contemplating, the truth predicate is defined for 'the language I understand' (it does not matter for present purposes whether this is a public language or the idiolect of a single individual); this can be taken, as I said before, as a paradigmatic case, where the relevant instances of the T-schema count as analytic. ${ }^{6}$ Let us call this language I. Given the previous considerations, a language such that an expression belonging to I, say, 'white', is used in a different way from the way it is used by competent speakers of I counts either as a different language (in the first version I gave of the reply to Putnani's argument) or as I-as-it-might-be, which is to be distinguished from I-as-itactually-is (in the second version). Let us call this language $\mathrm{I}^{*}$. With these conventions, $C_{1}$ can be unfolded in two different ways, as $C_{1 *}$ and as $C_{I^{\prime}}$ :

$\mathrm{C}_{\mathrm{I}^{*}}$ There is a possible language, $\mathrm{I}^{*}$, differing from $\mathrm{I}$ in the way the word 'white' is used, such that we might have used the word 'white' as it is used in $I^{*}$, and if we had used the word 'white' in that way, this would have had the following as a consequence: that 'grass is white' is true in I*.

$\mathrm{C}_{1}$, There is a possible language, $\mathrm{I}^{*}$, differing from $\mathrm{I}$ in the way the word 'white' is used, such that we might have used the word 'white' as it is used in I*, and if we had used the word 'white' in that way, this would have had the following as a consequence: that 'grass is white' is true in I.

$\mathrm{C}_{2}$ has only one relevant unfolding, as $\mathrm{C}_{2}$.

$\mathrm{C}_{2}$, There is a possible language, $\mathrm{I}^{*}$, differing from $\mathrm{I}$ in the way the word 'white' is used, such that we might have used the word 'white' as it is used in I*, and if we had used the word 'white' in that way, this would have had the following as a consequence: that grass is white.

Now, my point is in effect this: if we read $C_{1}$ as $C_{1^{*}}$, the cognitive equivalence of " "grass is white" is true' and 'grass is white' does not allow the inference to $\mathrm{C}_{2}$ ' and back. For 'grass is white' is only cognitively equivalent to " "grass is white" is true in I (is true as I understand it)", not to " "grass is white' is true in $I^{*}$ '. This inference is indeed allowed when $C_{1}$ is read as $C_{1^{\prime}}$; but, under that reading, the equivalence between $C_{1}$ and $C_{2}$ no longer expresses the idea of 'use-independence' that distinguishes minimalism. For, under that reading, the consequent of $C_{1}$ is 'disconnected' from the antecedent, as much as the consequent of $\mathrm{C}_{2}$ is from its own antecedent. Under that reading, $C_{1}$ no longer states the intuitively existing dependence of truth on meaning. It does not state the claim that, according to Putnam and other writers, should not be equivalent to an intuitive falsehood like $C_{2}$; for, read in this way, $C_{1}$ is intuitively as false as $C_{2}$.

To conclude this section, I need to examine critically an argument which Field has provided, purporting to establish that any predicate giving the benefits of semantic ascent must be 'minimal', that is to say, use-independent:

the use independence of disquotational truth is required for the purposes just reviewed [serving for semantic ascent, MG-C]. For if 'All sentences of lype $Q$ are true' is to serve as an infinite conjunction of all sentences of type $Q$, then we want it to entail each such sentence, and be entailed by all of them together. This would fail to be so unless ' $S$ is true' entailed and was entailed by $S$. But the only way that can be so is if 'true' doesn't ascribe a use-dependent feature to $S$. Suppose for instance that Euclidean geometry is true, and that we try to express its contingency by saying that the axioms together might have been false. Surely what we wanted to say wasn't simply that speakers might have used their words in such a way that the axioms weren't true, it is that space itself might have differed so as to make the axioms as we understand them not true. A use-independent notion of truth is precisely what we require (Field, 1994a, 266; see also Field, 1986, pp. 58-9).

If this argument were valid, there should be only one way to ensure that a modal claim, intended to be about Wittgenstein, made by referring to him by means of the description 'the author of the Tractatus', was in fact about him (instead of being about whoever in other possible circumstances might have written that book). By parity of reasoning, to guarantee that our intentions are satisfied we should perhaps stipulate that 'the author of the Tractatus' was to be understood according to a conventional, name-like relation between that expression and Wittgenstein-instead of understanding it as involving the 'indirect' ordinary relation that takes us from the expression to the man in virtue of the fact that he is the only individual satisfying the predicate 'author of the Tractatus'. However, there is a more common alternative already in use 
as part of our linguistic practices. If I say 'the author of the Tractatus might have been born in Argentina', in a context in which I transparently assume to be common knowledge between me and my audience that Wittgenstein, and he alone, wrote the Tractatus, and it is also clear from the context that there are reasons why I do not use a proper name or other referring expression (say, I have already used 'Wittgenstein' too much, or I do not suppose my audience to know the name), then I ought to be understood as making a modal cIaim about Wittgenstein. (In such a context, I am definitely not making a claim about a character from a possible short story by Borges, who writes the Tractatus, with all its words, oblivious to the existence and the deeds of the Austrian philosopher.)

Thus, Field's argument is invalid. Even a 'use-dependent' predicate, part of whose sense were that it applied to expressions of a specific language, individuated by its syntactic and semantic properties, could function as Field wishes, if that part were pragmatically discounted as not being included in what is asserted when making the kind of assertion that Field considers. A use-dependent predicate would be just as serviceable as a use-independent one-to the extent that whenever it was used with the communicative intentions indicated by Field, the semantic properties of the object-language sentences were intended to remain as part of the background common knowledge. (This obvious reply is considered in Field, 1986, pp. 58-9; I do not understand Field's rejoinder. Neither the obvious reply nor Field's rejoinder reappear in the more recent work, Field, 1994a, from where I quoted the argument.) Moreover, the fact that a use-dependent disquotational truth-predicate would be commonly used for the benefit of semantic ascent ouglit to be a reason for considering the semantic facts about the objectlanguage sentences, as it were by default, as part of the background common knowledge.

The point can perhaps be better appreciated by considering another version of Field's argument, due to Etchemendy:

the purpose of semantic ascent, despite its misleading name, is not the introduction of semantic topics into otherwise nonsemantic claims, but rather the indirect access that it gives us to the original, nonsemantic claims. [...] In most cases in which we use an ordinary truth predicate, specifically, those where the predicate functions as a device for semantic ascent, a Tarskian truth predicate wil serve equally well. Where such a predicate will fail is precisely when peculiarly semantic claims are at issue, for example in giving a semantic theory of a language. Thus, if I remark that, had 'snow is white' not been true, winter would have been a much more colorful season, my claim would be equally wel expressed with a Tarskian truth predicate. For here my intent is simply to assert, albeit indirectly, that had snow not been white; winter would have been much more colorful. In such cases, the very strong equivalence between 'snow is white' and " "snow is white" is true' is precisely what we would want; any introduction of semantic issues would be irrelevant and misleading. On the other hand, a Tarskian truth predicate will not allow us to make claims where the intent is distinctively semantic, say: Had 'snow' meant grass, 'snow is white' would not have been true. A Tarskian reformulation of this would turn it into nonsense; the meaning of 'snow' is, after all, completely irrelevant to the color of snow. [...] Tarski's eliminable concept of truth is fine for semantic ascent, but not for semantics (Etchemendy, 1988, Pp. 63-64; I have substituted throughout the sentences named for their names).

If the previous considerations are correct, this is confused. First and foremost, there is no way of separating semantic ascent from the sort of semantic claims Etchemendy has here in mind (it should be clear from the text that it is a linguistic theory of meaning which is here being contemplated, not a philosophical one). A predicate that can give the services of semantic ascent (a disquotational truth-predicate) is defined for a specific language, relative to the relevant semantic properties its expressions have. As a result, a disquotational truth-predicate involves, implicitly or explicitly, a reference to the language for which it is given.

Secondly, this implies, I think, as Field and Etchemendy indicate, that when a modal claim involving truth is made-" "snow is white' might not have been true (in L)'-the claim is semantically ambiguous. The descriptive element involved in the reference to the language can be taken with longer scope than the modal operator, thus obtaining the intended meaning (that snow might not have been white). Or, alternatively, it can be taken with narrower scope. In the latter case, it conveys something like this: there is a possible circumstance such that, either 'snow is white' has different semantic properties (in L as-it-might-have-been as opposed to as-it-actually-is, or in an altogether different language), so that it is outside the domain of the defined predicate, which therefore does not apply to it; or 'snow is white' has the same semantic properties in the circumstance, and snow is not white. (A similar ambiguity arises in Field's example regarding geometry.) It is true, as Etchemendy and Field say, that we only perceive the first interpretation in the examples they describe; but this can be explained pragmatically, on the basis that the context makes clear that the speaker does not intend to convey any semantic claim. (A reason for this, prominent in Field's example, is that the semantic claim is not interesting, whereas the geometric claim is.) Thus, these examples do not authorize the conclusion that a concept appropriate for semantic ascent is without semantic import (which I have independently argued to be incorrect). Even though it is true that in these cases, as Etchemendy says, 'any introduction of semantic issues would be irrelevant 
and misleading', there is a way of producing that effect which does not involve taking the equivalence between claims about the truth of a sentence and the claim made by the sentence as 'strong' as if the truth-predicate were 'use-independent'.

Finally, a Tarskian reformulation of semantic claims like "Had "snow" meant grass, "snow is white" would not have been true' does not turn them into nonsense. The only intuitive difficulty with Tarskian reformulations we can grant is perhaps that they make manifestly clear the extent to which, in the semantic conception of truth, the truth concept depends on the semantics of the object-language: a definition of truth for a language does not say anything about the conditions for application of a truth-predicate to a different language, or to a counterfactual counterpart of it slightly differing in semantic properties. However, this is as it should be, according to the semantic conception of truth; the yearning for a uniform, interlinguistic truthpredicate is misconceived, or misplaced. (There of course might still be philosophically interesting general commonalities between the strictly different truth-predicates; convention $\mathrm{T}$ is the most important.)

If the confusions I have been seeking to expose are real, there might be an interesting motivation (if not explanation) for them, from which at least a good lesson can be learnt. The main thrust of the argument in Field's classic paper (Field, 1972) makes it clear that what he expects from a theory of truth is a philosophical explanation of content, or meaning. Tarskian definitions of truth cannot (from that point of view) be explanatorily adequate, he claims, because they rely on definitions by enumeration of some semantic properties. He proposes an alternative, which he still thinks compatible with the core ideas of the semantic conception. However, other philosophers soon showed that, counting by his own standards of explanatoriness, his proposal does not pass muster either (see Soames, 1984, and Stalnaker, 1984, ch. 2). Both the title and the introductory comments in Field (1994a) show clearly that it is still a philosophical account of meaning (and a deflationary one at that) that Field is seeking to obtain from a theory of truth. If this is the goal, it is mandatory that the theory of truth be presented without assuming the concept of meaning, or related concepts. This makes at least understandable the emphasis put on substitutional quantification and analogous means.

Moreover, there is a philosophical tradition according to which those truthdefinitions that approach the ideal of homophony are somehow purely 'formal'. Thus, we frequently find in Davidson's writings claims like this: 'of course, a theory of truth is not treated as empirical if its adequacy is judged only in terms of the T-sentences it entails, and T-sentences are verified only by their form; this happens if we assume the object language is contained in the metalanguage' (Davidson, 1980, p. 73) And 'in those cases where the object language is contained in the metalanguage, the requirement [convention T] is merely syntactical: it tells us something about the predicates, but not much about the concept'. (Davidson, 1990, pp. 295-6). This view is also prominent in Quine's writings, as I hope to show elsewhere, particularly, in those cases when he resorts to disquotational ideas to somehow alleviate the well-known tension involved in putting together the thesis of the indeterminacy of translation and the claim that indeterminacy begins at home'. We have thus both some motivation for 'use-independence', and a suggestion that, still without making 'uncritical' use of semantic concepts, we could obtain a definition of truth.

This line of thought should be mistaken, if the previous arguments are sound; I develop it only to make more acceptable the ascription of philosophical confusion to well-known writers on truth, by making the confusion explainable. Of course, we should not confuse the fact that a competent user of a language could test the material adequacy of a truthdefinition for his language in a language which includes it only on the basis of his semantic competence, with the idea that the defined concept is 'formal', or 'use-independent' in any interesting way. And we have some reasons for doubting the coherence of using a disquotationally understood truth-predicate to offer a philosophical account of the content of the truthbearers (as opposed to a mere redescription of content as 'truth-conditions')

\subsection{Some other problems with minimalism}

In the previous section I have set out what I take to be the main difficulty of minimalist views. I want to conclude by considering some secondary ones, all of which arise from the main one. If a disquotational explication of truth is committed to the tenets of the semantic conception, it can only be given for interesting fragments of a language by including in effect elements of the explanations provided by linguistic theories of meaning. In trying to avoid this, minimalist accounts should run into trouble; and, in my view, they do. In this concluding section, I just want to give the flavour of the problems by presenting two cases. ${ }^{7}$

First, indexicality is a pervading phenomenon which can be plausibly thought essential to the way natural language works (compare Burge, 1977) and which, in any case, permeates most ordinary statements. But no minimalist theory of truth can correctly account for our intuitions regarding truth-predications of indexical utterances we understand. Just consider, as an amusing example suggestive of the sort of difficulty indexicals pose for 
minimalism, the T-sentence which, according to minimal standards, allegedly captures the content of a truth predication of an utterance of 'this sentence is not a biconditional'.

I find what deflationists like Field or Horwich say about this unconvincing. Take Field. On the one hand, we find him recalling, in good minimalist spirit, that

As I have explained disquotational truth, axiomatic status is given to some generalized version of the truth schema:

(T) ' $p$ ' is true if and only if $p$.

The generalized version might be the result of prefixing the schema with universal substitutional quantifier; alternatively, we might prefer the weaker approach involving schematic variables, mentioned earlier (Field, 1994a, p. 267)

On the other, he appears to have forgotten this entirely when he considers how to explain truth-predications of utterances including indexicals:

nothing stops us from applying talk of disquotational truth conditions to tokens: once we remember that 'disquotationally true' means 'true-as-I-interpret-it', the obvious rhing to say is that an utterance of ' $p\left(i_{1}, \ldots, i_{n}\right)$ ' is disquotationally true (for $m e$, that is, as I understand it) iff the sentence is true relative to the values of $a_{1}, \ldots, a_{n} I$ regard as appropriate to associate with the indexicals (Field, 1994a, p. 280).

Field proposes two stages to take care of sentences with indexicals, one in which a relativized truth-concept is defined for the sentence-type ' $p\left(\mathrm{i}_{1}, \ldots, \mathrm{i}_{n}\right)$ ' relative to a given assignment to ' $a_{1}$ ', ., ' $a_{n}$ ', in terms of $p\left(a_{1}, \ldots, a_{n}\right)$, and a second stage in which the unrelativized truth of a token is defined by selecting the appropriate assignment. Now, there need not be anything objectionable in applying disquotational truth to tokens, but where is the definition that would allow us to understand general predications of unrelativized truth whose domain includes indexical utterances, as in the useful cases of 'semantic ascent'? Certainly, the 'generalized version of the truth schema' to which 'axiomatic status' is given is of no help here.

Horwich's proposal is even more clearly inadequate. As I said before, he spends most of his book (Horwich, 1990) discussing a version of propositional minimalism. Nevertheless, he promises at the very beginning of the book that he will provide an account of truth for utterances which he advertises to be as 'disquotational' as the one he claims to give for propositions, but defined independently of the account for propositions. What we finally find (motivated on account of the difficulties provoked by indexicality we have just reviewed) is the following schematic characterization of the axioms of the theory of truth for utterances:
Thus the correct form of the disquotational schema is:

(D) This ('p') is true iff $\mathrm{p}$

where 'This (' $\mathrm{p}$ ')' refers to the instance of 'p' that occurs on the other side of the biconditional (Horwich, 1990, p. 105)

As a device for 'semantic ascent', though, a predicate specified according to this theory is utterly unserviceable. It cannot give any content at all to an assertion such as 'something uttered by Felipe yesterday is true'; for the truthpredicate has been stipulated to apply only to the concrete utterances appearing as the right-hand sides of the theory's axioms, and, therefore, the definition gives no clue about whether the defined predicate applies or does not apply to any of Felipe's utterances. (Unless Felipe, perhaps a logic student, happened to utter an instance of (D); and even then the definition only puts conditions on the application of 'true' to a part of what he uttered, the right-hand side of the relevant instance of (D), and not to the whole of his utterance.)

The second secondary consideration I want to present is the following. As has been repeatedly pointed out by philosophers such as Frege, Wittgenstein and Davidson, and also by linguists like Chomsky, linguistic competence is 'productive'. (I use this word in the vague way psychologists tend to use it, embracing the two phenomena that Fodor (1987) distinguishes under the labels of 'systematicity' and 'productivity', or perhaps intending only the former, the weaker of the two.) This productivity manifests itself, as Evans (1981) perspicuously showed, in specific patterns of acquisition and losses. If a new lexical unit-say, the root of a verb-were added to our competence (because, although it already belonged to the public language we try to conform our practice to, we had not encountered it previously, or simply because it has recently been added to it by explicit agreement), this would involve thereby, as it were ipso facto, a predictable addition of new words, sounding according to predictable phonetic patterns, and a predictable addition of new well-formed sentences, each expressing predictable new meanings. Similar subjunctive contentions could be inade, mutatis mutandis, about pattems of loss following the loss of a lexical unit. Of course, being able to accurately state those predictions would require having a precise theory of the systematic articulation of our language-which we are very far away from possessing. And to speak of definite patterns of generalization as I have done may suggest the view that linguists tend to take uncritically for granted, namely, that human languages have more determinate and general phonological, morphological, syntactical and semantical rules than they in fact appear to have. But, once properly qualified, the hypothesis that linguistic 
competence is productive appears to be as well-supported by empirical facts as any we accept.

Now, the interesting point for our present concerns is that our competence involving 'true', as a predicate applying to utterances of sentences we already understand-a predicate which vindicates the analyticity of paradigm instances of the T-schema characteristic of those core cases of pure disquotational truth-mirrors the productivity of our semantic competence. That is to say, any new sentence which, given that articulation of our semantic competence that correctly accounts for the productive nature of our linguistic mastery, is the reby assigned a meaning once a new lexical unit is added to the competence, seems to be, no less immediately, thereby a proper substituent for ' $p$ ' in the disquotational schema $<<$ ' $p$ ' is true iff $p>$. Our intuitions indicate that this is so even when the issue of indexicality is left aside, and the language is taken to consist only of 'eternal sentences'-like the language that Tarski chose to illustrate how to construct interesting truth-definitions in 'The Concept of Truth in Formalized Languages', $\$ \S 2-3$. Now, a truth-definition given by resorting to substitutional quantification is ill-prepared to account for this fact. ${ }^{8}$ The reason is that the truth-definition in no way engages the semantic compositional theory for the object-language, whatever it is, which accounts for the productive nature of our semantic competence. A proper definition by substitutional quantification simply takes for granted a previously specified (no matter how) substitutional class.

The class which constitutes the domain for substitutional quantifiers must be fixed to avoid the semantic antinomies (see Kripke, 1976). But the problem I am pointing at does not arise from the fact that the language for which truth is defined by means of substitutional quantification is fixed, for this is also the case with respect to the sort of alternative disquotational theory I am envisaging-namely, the one exemplified by interesting Tarskian theories of the sort already mentioned. They are also given for fixed languages, in part for similar reasons (to avoid the antinomies) and in part on account of the fact that semanticist disquotational definitions are given, as we saw, for languages precisely individuated both syntactically and semantically. The difference lies in the fact that, because interesting Tarskian theories rely, at least in part, on the compositional semantics for the language, they indirectly assign to 'true' the same productive structure that the compositional semantic theory assigns to the object language-a productive structure that entails definite predictions about what happens after the incorporation of new expressions or the loss of old ones. These predictions about the path along which the language would evolve (turning into different but structurally related languages) indirectly entail predictions about how truth-predicates whose definitions engage the compositional semantic structure of the object language would evolve. And these predictions, indirectly entailed, are the ones which our intuitions regarding what for disquotationalists are the core cases for application of 'true' validate.

Some other writers have emphasized what I take to be concrete aspects of the general problem I have tried to put forward. Thus, Anil Gupta has made it clear that minimalist theories cannot account for general claims about truth that we find intuitively acceptable, and that semantic theories along the lines that Tarski showed how to construe do account for generalizations such as: if a conjunction is true, its two conjuncts are true (see Gupta, 1993).

As a final relevant consideration, there are some apparent consequences of minimalist disquotationalism, happily embraced by some friends of minimalism which seem obviously misguided. (The following point is also made in Jackson et al., 1994). Consider, for introductory purposes, a particularly blatant instance of the kind of confusion I have in mind. Let us assume that the semantics of their language is not wholly 'transparent' to competent speakers, in that there could be cases of the Tractarian 'unsinnig': declarative sentences which seem to have content, but in fact lack it. This is a possibility ordinarily granted; I think it is also compatible with both 'realist' and 'antirealist" metaphysical theories of meaning. Take $S$ as such a sentence. Thus, $S$ is neither acceptable nor non-acceptable, no matter what our semantic viewpoints are: it has the same status as gibberish, even though it is not gibberish. $\mathrm{S}$ does not put any condition that the world might satisfy or not satisfy; it does not specify conditions for its warranted assertion or refutation. In that case, I take it, even if 'true' has been defined according to the semantic conception, ' $S$ is true' will be similarly neither true nor false. Of course, because ' $S$ is true' is cognitively equivalent to $S$, he who incorrectly thinks that $S$ has content will take ' $S$ is true' as having the same truth-value he assigns to $S$, true, false or unknown; but this is a point about his (confused) beliefs regarding the application of 'true', not about the application of 'true' itself (which is entirely determined by the biconditional entailed by the truthdefinition, and by the facts about the sentence which have been used to give its truth-condition).

However, minimalism seem to entail the opposite, and some of its friends seem to agree. They in fact contend that, because 'true' has been minimally specified, ' $S$ is true' will have a truth-value, irrespective of the semantic impropriety of $S$. They do not consider examples of the sort I have mentioned; but what they say about similar cases is analogously unacceptable. Suppose, however, that ' $P$ ' is vague, ' $a$ ' means something in the penumbral region of its domain, and ' $\neg$ ' expresses negation. Then, for exactly the same 
reasons as given before, even if 'true' had been defined by means of a disquotational condition, both " $\mathrm{Pa}$ " is true' and " $\neg \mathrm{Pa}$ " is true' should be neither true nor false. The same will be the case if ' $\mathrm{Pa}$ ' only looks like a declarative sentence, but is not in fact one. Suppose that $S$ is semantically indeterminate; it could have either one of two possible contents, and there is no fact of the matter about which it has. Then the same indeterminateness will attach, in the presence of the truth-definition, to ' $S$ is true'. If, as a consequence of its semantic indeterminacy, $S$ is referentially indeterminate (indeterminate in truth-value), exactly the same condition will accrue to ' $\mathrm{S}$ is true'. (The same could be said, mutatis mutandis, regarding referential indeterminacy for other types of expression arising from their semantical indeterminacy-i.e., 'rabbit' $-v i s$ - $\grave{a}$-vis a disquotationally specified definition of reference for expressions of that type. No such specification of reference for predicates can make the reference of 'rabbit' less indeterminate than the expression by means of which we fix it, i.e., 'rabbit'.)

Philosophers who take minimalism as the proper way to understand disquotationalism, however, make opposite claims. (See Field, 1986, II.2, Field, 1994a, p. 260, the works by Boghossian and Wright discussed in Jackson et al., 1994, and Loar, 1995). Quine has made similar claims on how a disquotational account of truth and reference might somehow alleviate the most startling consequences of his indeterminacy thesis. In the face of the argument before, it is difficult to make sense of these contentions. (I should say that Field, 1994b valiantly and illuminatingly confronts some of the difficulties mentioned in this section.)

Although no proper defence of disquotational views has been attempted here, in view of the deficiencies of minimal theories, thus, disquotationalists should resort to semantic ways when they try to reconstruct by means of an explicit definition our tacit understanding of 'truth' as a predicate of utterances of the sentences of our language, which gives the services of semantic ascent. Tarski himself, of course, indicated the path to follow. Field (Field, 1986, I.4; Field, 1994a, \$6) points out three difficulties for this task. The first is based on the previously discussed argument he gives to justify the 'independence from use' that according to him disquotational truth-predicates should have; I think 1 have already answered this concern. The second consists simply in pointing out that, even granting the successes of Tarski himself and later researchers (mostly, in the Davidsonian tradition), we cannot have any certainty that a Tarskian truth-definition could be framed for significant fragments of our language. The third is that, to avoid the paradoxes, all known theories include restrictions that involve some departure from the paradigm cases instantiated by toy definitions of the kind
Tarski invoked to exemplify his ideas in 'The Concept of Truth in Formalized Languages', $\S \S 2-3$. These two latter criticisms are fair enough. Indexicality could also be mentioned here, for it not only raises concerns for minimalism but also for the present undertaking. On the other hand, I think that some considerations can be advanced at least to allay each of these three worries (but will refrain from doing so here). On the whole, I think that disquotationalism is a sensible hypothesis, supported by our intuitions regarding the analyticity of T-sentences and the usefulness of the intuitive truth-predicate as a device for semantic ascent. Disquotationalism is in summary the conjecture that truth is primarily a predicate of utterances of the sentences of our language that serves for semantic ascent, our tacit knowledge of which cannot be explicitly construed by means of a minimal definition but by resorting to the compositional nature of the object-language, in the way shown by Tarski.

\section{Notes}

* $\quad$ Financial support has been provided as part of the research project PS94-0244, funded by the DGICYT, Spanish Ministry of Education.

1 There is, moreover, at least one philosophical programme (Grice's) which purports to offer a philosophical account of the meaning of utterances without using the concept of truth. Rumfitt (1995) offers an interesting argument for the thesis that a philosophical account of meaning should use the concept of truth, but I cannot attempt to give a rejoinder here. And, of course, Donald Davidson has provided arguments for the same claim; I have only argued against the force of considerations like the ones quoted before.

2 I reply to these arguments in García-Carpintero, forthcoming-a.

3 Horwich's 'proper formulation' is astoundingly simple (anglebrackets are devices to construct names of the propositions expressed by the sentences they flank): 'The axioms of the theory are [...] all the propositions whose structure is $\left(\mathrm{E}^{*}\right)<<\mathrm{p}>$ is true iff $\mathrm{p}>$. [...] This [...] is a propositional structure. It is a function from propositions to propositions. Thus if $\left(\mathrm{E}^{*}\right)$ is applied to the proposition <snow is white $>$ it yields the proposition 《snow is white $>$ is true iff snow is white>'. (Horwich, 1990, pp. 18-20). However, if (E*) truly defined a function from abstract entities (propositions) intro abstract entities, it should specify a value for every entity in the domain independently of the way the argument was given. A function from numbers into numbers is not properly defined if it only assigns a value to a number 
when the number is given in a certain way. On the face of it, $\left(E^{*}\right)$ only assigns a value to a proposition when the proposition is given by a sentence that expresses it, not when it is named in any other way. Moreover, because Horwich refuses to say anything about the nature of propositions, we cannot even be sure about the value of $\left(E^{*}\right)$ for a proposition given in a proper way. For instance, if propositions are sets of possible worlds, $<2+2=4>=<$ arithmetic is incomplete $>$. Should we understand then that both ' $<<2+2=4>$ is true iff $2+2=4>$ ' and ' $<<$ arithmetic is incomplete $>$ is true iff $2+2=4>$ ' name the ( $\left.E^{*}\right)$ value for $<2+2=4>$ (i.e., the axiom giving the conditions for application of 'true' to $<2+2=4>$ )? We cannot tell. The reader should realize that the axioms of the theory are supposed to be the propositions named by expressions like ' $<<2+2=4>$ is true iff $2+2$ $=4>$ ' themselves, not propositions-as-named-by-expressions-ofcertain-sorts. An axiom of the theory is a biconditional proposition. Notice that the biconditional is a propositional constituent here, not an expression; it has, on its 'left-hand side', a proposition consisting of the predication of the truth of a certain proposition, and, on its 'righthand side' the same proposition. (Notice also that the 'sides' are structural components of propositions, to be theoretically specified.) This characterization, by itself, leaves it indeterminate whether ' $<$ arithmetic is incomplete is true iff $2+2=4$ >' names such an axiom. Actually, in personal conversation Paul Horwich told me that he intended the axioms to be necessarily specified by putting the same sentence in both 'p' positions. Suggestions such as this indicate that it is linguistic minimalism that Horwich has ultimately in mind. (I owe the main points in this footnote to my colleague, Ignacio Jané.)

Horwich has made these claims in a paper delivered at the SOFIA conference on truth in Querétaro, México, June 17-19, to appear in Villanueva, E. (ed.). Philosophical Issues, Vol. 8.

5 Horwich says that he gives his minimal definition for propositions because he is not willing to resort to substitutional quantification.

6 Subtle questions regarding the analyticity of T-sentences are developed in García-Carpintero, forthcoming-b.

7 See David, 1994, ch. 5, for a number of related criticisms. My disagreement with this work lies only in its contraposition of what there are called 'correspondence' theories and disquotational theories. The author assumes that a disquotational account should be identified with a minimalist one (perhaps because the most outspoken defender of disquotationalism, Quine, is-accidentally-also a minimalist). Her careful and interesting attempts at formulating 'disquotationalism' are in fact attempts at formulating minimalism-the view that tries to frame disquotational ideas with a minimal use of semantic concepts. Such view, if my arguments in the previous section succeed, is doomed to issue inconsistent claims. However, the two elements in it should be separated. As I would like to show in a longer work, the semantic conception may properly capture disquotationalism, while happily making use of a heavy semantic machinery (while, in fact, including a linguistic theory of meaning for the object language). Moreover, when properly so developed, the semantic conception turns out to be not only disquotational, but also a correspondence theory by David's lights.

8 As is one given for propositions in the way that Horwich does.

\section{References}

Burge, T. (1977), 'Belief de re', Journal of Philosophy, 74, pp. 338-362.

David, M. (1994), Correspondence and Disquotation, Oxford University Press: Oxford.

Davidson, D. (1980), 'In Defense of Convention T', in Davidson, D., Inquiries into Truth and Interpretation, Oxford University Press: Oxford, pp. 65-75.

(1990), 'The Structure and Content of Truth', Journal of Philosophy, Vol. 87, pp. 279-327

Dummett, M. (1978), 'Preface', in his Truth and Other Enigmas, Harvard University Press: Cambridge, Mass.

- $(1996 \mathrm{~ms})$, 'Is the Concept of Truth Needed for Semantics?'. Paper delivered to the conference Verdad, representación y mundo, held at the University of Santiago de Compostela, January, pp. 17-20.

Etchemendy, J. (1988), 'Tarski on Truth and Logical Consequence', Journal of Symbolic Logic, Vol. 53, pp. 51-79.

Evans, G. (1981), 'Semantic Theory and Tacit Knowledge', in his Collected Papers, Clarendon Press: Oxford.

Field, H. (1972), 'Tarski's Theory of Truth', Journal of Philosophy, 69, pp. $347-375$

- (1986), 'The Deflationary Conception of Truth', in MacDonald, G. and Wright, C. (eds), Fact, Science and Morality, Basil Blackwell: Oxford, pp. 55-117.

__ (1994a), 'Deflationist views of Meaning and Content', Mind, Vol. 103, pp. 249-285. 
- (1994b), 'Disquotational Truth and Factually Defective Discourse', Philosophical Review, Vol. 103, pp. 405-452.

Fodor, J. (1987), Psychosemantics, appendix 'Why There Still Has to Be a Language of Thought', MIT Press: Cambridge, Mass.

García-Carpintero, M. (1994), 'Two Varieties of Disquotationalism', Villanueva, E. (ed.), Truth and Rationality. Philosophical Issues, Vol. 5, Ridgeview Publishing Company: Atascadero, Ca., pp. 177-188.

- (1996), 'What Is a Tarskian Theory of Truth?', Philosophical Studies, Vol. 82, pp. 113-144.

- (forthcoming-a), 'The Explanatoriness of Disquotational Truth Theories', to appear in Peregrin, J. (ed.), The Nature of Truth, if Any, Academy of Sciences of the Czech Republic: Prague, pp. 17-20.

- (forthcoming-b), 'An Incorrect Understanding of Tarskian Truth Definitions: Comments on Soames 'The Truth of Deflationism', to appear in Villanueva, E. (ed.), Philosophical Issues 8: Truth.

- (ms): 'Disquotationalism in the Face of the Indeterminacy Thesis'.

Gemes, K. (1991), 'The Indeterminacy Thesis Reformulated', Journal of Philosophy, Vol. 1-36, pp. 91-108.

Gupta, A. (1993), 'A Critique of Deflationism', Philosophical Topics, Vol. 21, pp. 57-81.

Horwich, P. (1990), Truth, Basil Blackwell:Oxford.

Jackson, F., Oppy, G. and Smith, M. (1994), 'Minimalism and Truth Aptness', Mind, Vol. 103, pp. 287-302.

Kripke, S. (1976), 'Is There a Problem about Substitutional Quantification?', in Evans, G. and McDowell, J. (eds), Truth and Meaning: Essays in Semantics, Oxford University Press: Oxford, pp. 325-419.

Leeds, S. (1978), 'Theories of Reference and Truth', Erkenntnis, Vol. 13, pp. 111-129.

Loar, B. (1995), 'Semantic Determinacy from the First Person Perspective' Philosophical Issues, Vol. 6, Villanueva, E. (ed.), Ridgeview Publishing Company: Atascadero, Ca.

McDowell, J. (1976), 'Truth Conditions, Bivalence and Verificationism', in Evans, G. and McDowell, J. (eds), Truth and Meaning, Clarendon Press: Oxford, pp. 42-66.

Putnam, H. (1985), 'A Comparison of Something with Something Else', New Literary History, Vol. 17, pp. 61-79.

Quine, W. V. O. (1970), Philosophy of Logic, Harvard University Press: Cambridge, Mass

(1987), Quiddities, Harvard University Press: Cambridge, Mass,

Rumfitt, I. (1995), 'Truth and Communication', Mind, Vol. 104, pp. 827-862.
Soames, S. (1984), 'What is a Theory of Truth?', Journal of Philosophy, Vol. 1, No. 81, pp. 411-429.

- (forthcoming), 'The Truth about Deflationism', to appear in Villanueva, E. (ed.), Philosophical Issues. Truth., Vol. 9.

Stalnaker, R. (1984), Inquiry, MIT Press: Cambridge, Mass.

Tarski, A. (1935), 'The Concept of Truth in Formalized Languages', in Tarski, A., Logic, Semantics, Metamathematics, Corcoran, J. (ed.) (1983), Hackett Pub. Co.: Indianapolis, pp. 152-268. Originally published in German in 1935.

\section{Acknowledgements}

Comments by Eduardo Barrio, José Antonio Díez, Eleonora Orlando, Michel Seymour and Ernesto Sosa on a previous version of this paper were of great help in preparing the present one. 